\title{
Genetic variations in merozoite surface antigen genes of Babesia bovis detected in Vietnamese cattle and water buffaloes
}

\author{
Naoaki Yokoyama ${ }^{a}, *$, Thillaiampalam Sivakumar ${ }^{a}$, Bumduuren Tuvshintulga ${ }^{a}$, Kyoko Hayashida ${ }^{a}$, \\ Ikuo Igarashi ${ }^{\mathrm{a}}$, Noboru Inoue ${ }^{\mathrm{a}}$, Phung Thang Long ${ }^{\mathrm{b}}$, Dinh Thi Bich Lan ${ }^{\mathrm{c}}$ \\ ${ }^{a}$ National Research Center for Protozoan Diseases, Obihiro University of Agriculture and Veterinary Medicine, Obihiro, Japan \\ ${ }^{\mathrm{b}}$ Hue University of Agriculture and Forestry, Hue, Vietnam \\ ${ }^{\mathrm{c}}$ Institute of Biotechnology, Hue University, Hue, Vietnam
}

\section{A R T I C L E I N F O}

\section{Article history:}

Received 9 November 2014

Received in revised form 25 December 2014

Accepted 29 December 2014

Available online 6 January 2015

\section{Keywords:}

Babesia bovis

Cattle

Genetic diversity

Merozoite surface antigen genes

Vietnam

Water buffalo

\begin{abstract}
A B S T R A C T
The genes that encode merozoite surface antigens (MSAs) in Babesia bovis are genetically diverse. In this study, we analyzed the genetic diversity of $B$. bovis $M S A-1, M S A-2 b$, and MSA-2c genes in Vietnamese cattle and water buffaloes. Blood DNA samples from 258 cattle and 49 water buffaloes reared in the Thua Thien Hue province of Vietnam were screened with a $B$. bovis-specific diagnostic PCR assay. The $B$. bovis-positive DNA samples (23 cattle and 16 water buffaloes) were then subjected to PCR assays to amplify the MSA-1, MSA-2b, and MSA-2c genes. Sequencing analyses showed that the Vietnamese MSA1 and $M S A-2 b$ sequences are genetically diverse, whereas $M S A-2 c$ is relatively conserved. The nucleotide identity values for these MSA gene sequences were similar in the cattle and water buffaloes. Consistent with the sequencing data, the Vietnamese MSA-1 and MSA-2b sequences were dispersed across several clades in the corresponding phylogenetic trees, whereas the MSA-2c sequences occurred in a single clade. Cattle- and water-buffalo-derived sequences also often clustered together on the phylogenetic trees. The Vietnamese MSA-1, MSA-2b, and MSA-2c sequences were then screened for recombination with automated methods. Of the seven recombination events detected, five and two were associated with the $M S A-2 b$ and MSA-2c recombinant sequences, respectively, whereas no MSA-1 recombinants were detected among the sequences analyzed. Recombination between the sequences derived from cattle and water buffaloes was very common, and the resultant recombinant sequences were found in both host animals. These data indicate that the genetic diversity of the MSA sequences does not differ between cattle and water buffaloes in Vietnam. They also suggest that recombination between the B. bovis MSA sequences in both cattle and water buffaloes might contribute to the genetic variation in these genes in Vietnam.
\end{abstract}

(c) 2015 Elsevier B.V. All rights reserved.

\section{Introduction}

Babesia bovis is an intraerythrocytic protozoan parasite that infects cattle and buffaloes (Bock et al., 2004). The parasite is transmitted by ixodid ticks and is predominantly prevalent in tropical and subtropical regions of the world (Smith et al., 2000). B. bovis often causes severe clinical disease in cattle, and is therefore considered a virulent species of Babesia (Ristic, 1981). In addition to the fever, anemia, and jaundice that are commonly associated with Babesia infections in host animals, B. bovis-infected cattle can

* Corresponding author at: National Research Center for Protozoan Diseases, Obihiro University of Agriculture and Veterinary Medicine, Inada-cho, Obihiro, Hokkaido 080-8555, Japan. Tel.: +81 15549 5649; fax: +81 155495643.

E-mail address: yokoyama@obihiro.ac.jp (N. Yokoyama). display neurological signs and a respiratory disease syndrome (Everitt et al., 1986). Failure of early diagnosis and treatment may lead to deaths among affected animals (Bock et al., 2004). Therefore, the disease has serious economic implications for cattle farming. Live attenuated vaccines are commercially available in a number of endemic countries, with which susceptible cattle populations can be immunized against this parasite (Shkap et al., 2007), but live attenuated vaccines are not without risks.

One of the major problems associated with the use of live vaccines is vaccine breakthrough, which is thought to be attributable to differences between the vaccine strains and field isolates (Bock and de Vos, 2001). In Australia, analysis of the merozoite surface antigen genes (MSAs) of vaccine strains and outbreak isolates have revealed marked differences between them (Berens et al., 2005; Leroith et al., 2005). Furthermore, recombinant MSA-1 antigens 
prepared according to the nucleotide sequences of outbreak isolates and vaccine strains failed to react with sera collected from the vaccinated animals and from animals that had experienced the outbreaks, respectively (Leroith et al., 2005). These observations have prompted researchers to conclude that the genetic diversity of MSAs might play a role in strain-dependent immunity to $B$. bovis (Berens et al., 2005; Leroith et al., 2005). Therefore, immune control strategies against $B$. bovis infection must be designed with reference to their genetic diversity. The MSAs are also recognized as candidate antigens for the development of subunit vaccines (Brown and Palmer, 1999; Hines et al., 1992; Palmer and McElwain, 1995). Therefore, analysis of the genetic makeup of these genes in different isolates should generate important data to evaluate the implications of using MSAs as vaccines.

Against this background, the genetic diversities of MSAs (MSA-1, $M S A-2 b$, and $M S A-2 c$ ) have been analyzed in several $B$. bovis-endemic countries in the recent past (Altangeral et al., 2012; Genis et al., 2008, 2009; Sivakumar et al., 2013b). Studies conducted in Australia (Berens et al., 2005; Leroith et al., 2005), Sri Lanka (Sivakumar et al., 2013b), the Philippines (Tattiyapong et al., 2014), Thailand (Simking et al., 2013), Israel (Molad et al., 2014), Brazil (Nagano et al., 2013), and Mexico (Borgonio et al., 2008; Genis et al., 2008, 2009 ) have found that $B$. bovis isolates in these countries are genetically diverse, according to their MSA gene sequences.

Buffaloes are thought to play an important role in the epidemiology of B. bovis (da Silva et al., 2013; Elsify et al., 2015; He et al., 2012; Sivakumar et al., 2013a). However, although MSA genes have been widely used for strain verification in B. bovis, they have rarely been compared between cattle and buffaloes.

Vietnam is an agriculturally rich country, and several species of Babesia and Theileria are reported in its livestock populations, including cattle and water buffaloes (Geurden et al., 2008; Khukhuu et al., 2011; Sivakumar et al., 2013a). Although Sivakumar et al. (2013a) recently analyzed the genetic diversity of the $B$. bovis $M S A-2 b$ gene in Vietnam, only a few gene sequences were examined in that study. Therefore, in the present study, we determined larger numbers of MSA-1, MSA-2b, and MSA-2c gene sequences in $B$. bovis derived from Vietnamese cattle and water buffaloes, and analyzed their genetic diversity.

\section{Materials and methods}

\subsection{Blood sampling and DNA extraction}

Blood samples were collected from 258 cattle and 49 water buffaloes reared in Thua Thien Hue province of Vietnam during the period from January to March 2013. The blood samples were drawn from the jugular veins of the animals into Vacutainer tubes containing an anticoagulant. All the cattle and water buffaloes were apparently healthy at the time of sampling. DNA was extracted from all the blood samples with a commercial kit (QIAamp DNA Blood Mini Kit, Qiagen, Hilden, Germany), according to the manufacturer's instructions. The DNA samples were then stored at $-30{ }^{\circ} \mathrm{C}$ until analysis.

\subsection{PCR detection of $B$. bovis}

All the DNA samples were screened for B. bovis DNA using a previously described nested PCR assay based on the rhoptry-associated protein 1 (RAP-1) gene (Figueroa et al., 1993). The reaction mixtures and cycling conditions were essentially as described by Sivakumar et al. (2012b). The PCR products were then analyzed with agarose gel electrophoresis followed by ethidium bromide staining, and visualized under UV light. The detection of a band close to 298 bp was considered positive for B. bovis.
2.3. Amplification and sequencing of the MSA-1, MSA-2b, and MSA-2c genes

All the B. bovis-positive DNA samples collected from the cattle and water buffaloes were subjected to PCR assays to amplify the $M S A-1, M S A-2 b$, and $M S A-2 c$ genes, as described previously (Sivakumar et al., 2013b). Two forward primers (MSA-1 F1 and MSA-1 F2) were used to amplify the MSA-1 gene in two separate PCR assays, while $M S A-2 b$ and $M S A-2 c$ genes were amplified using single forward primers (MSA-2a1/2a2/2b F and MSA-2c F, respectively), as described by Sivakumar et al. (2013b). In addition, a single reverse primer (MSA R) was used to amplify all three genes (MSA-1, MSA-2b, and MSA-2c) (Sivakumar et al., 2013b). The PCR reaction mixtures and cycling conditions have been described in previous reports (Sivakumar et al., 2013b; Tattiyapong et al., 2014). The amplified gene fragments were gel-extracted and cloned as described previously (Sivakumar et al., 2012a). For each cloned product, three clones were picked and both DNA strands of each were sequenced.

\subsection{Sequence analysis}

The genetic diversity of the sequences determined in the present study was analyzed with the DnaSP v5 software (Librado and Rozas, 2009). The identity values among the nucleotide sequences were calculated using the MatGAT software program (Campanella et al., 2003). In addition, $M S A-1, M S A-2 b$, and $M S A-2 c$ gene sequences were converted to amino acid sequences and then subjected to B-cell epitope prediction, as described by Kolaskar and Tungaonkar (1990) (http://tools.immuneepitope.org/bcell/). Possible recombination events among the gene sequences were detected with the RDP4 Beta 4.39 software (Martin and Rybicki, 2000), which uses seven automated recombination detection methods: RDP (Martin and Rybicki, 2000), Geneconv (Padidam et al., 1999), Bootscan (Martin et al., 2005), MaxChi (Maynard Smith, 1992), Chimaera (Posada and Crandall, 2001), SiScan (Gibbs et al., 2000), and 3Seq (Boni et al., 2007). Only the recombinations detected by at least three of these programs were considered to reflect possible recombination events. For each recombination event detected with the software, phylogenetic trees were constructed with the RDP4 Beta 4.39 program using the portions of the sequence between the recombination breakpoints, and were analyzed to confirm the positions of the major and minor parental sequences in relation to the recombinant sequence.

\subsection{Phylogenetic analyses}

The newly determined MSA-1, MSA-2b, and $M S A-2 c$ gene sequences, together with the relevant gene sequences already available in GenBank, were used to construct three separate phylogenetic trees. For the phylogenies of $M S A-2 b$ and $M S A-2 c$ genes, only the representative (Vietnamese) sequences were used, if the sequences from a single PCR amplicon shared high identity values. The online MAFFT software program (Katoh et al., 2002) was used to construct neighbor-joining phylogenetic trees (Saitou and Nei, 1987) based on the Jukes-Cantor substitution model (Jukes and Cantor, 1969).

\section{Results}

Of the 258 cattle and 49 water buffalo blood DNA samples, 23 (8.9\%) and 16 (32.7\%) were positive for B. bovis, respectively, according to the RAP-1-based nested PCR assay. All the B. bovispositive DNA samples were subjected to PCR assays to amplify 
Table 1

GenBank accession numbers for the MSA-1, MSA-2b, and MSA-2c gene sequences identified in the present study.

\begin{tabular}{|c|c|c|c|c|}
\hline \multirow[t]{2}{*}{ Animal type } & \multirow[t]{2}{*}{ Animal ID } & \multicolumn{3}{|l|}{ GenBank accession numbers } \\
\hline & & MSA-1 & $M S A-2 b$ & $M S A-2 c$ \\
\hline \multirow[t]{12}{*}{ Cattle } & $\mathrm{C} 22$ & & & LC004339 \\
\hline & $\mathrm{C} 28$ & LC004298, LC004299 & LC004307, LC004308 & LC004340, LC004341, LC004342 \\
\hline & C63 & & LC004309, LC004310 & LC004343, LC004344, LC004345 \\
\hline & $\mathrm{C} 78$ & & LC004311, LC004312, LC004313 & \\
\hline & C79 & & LC004314, LC004315, LC004316 & LC004346, LC004347, LC004348 \\
\hline & C109 & & LC004317, LC004318, LC004319 & LC004349, LC004350 \\
\hline & $\mathrm{C} 122$ & & LC004320, LC004321 & LC004351, LC004352, LC004353 \\
\hline & $\mathrm{C} 124$ & LC004300 & LC004322 & LC004354, LC004355 \\
\hline & C164 & & & LC004356, LC004357 \\
\hline & $\mathrm{C} 176$ & & LC004323, LC004324 & LC004358, LC004359 \\
\hline & C187 & LC004301, LC004302, LC004303 & LC004325, LC004326 & LC004360, LC004361 \\
\hline & C202 & & LC004327, LC004328, LC004329 & LC004362 \\
\hline \multirow[t]{6}{*}{ Water buffalo } & $\mathrm{B} 21$ & & & LC004363, LC004364 \\
\hline & $\mathrm{B} 23$ & LC004304, LC004305 & LC004330 & LC004365, LC004366, LC004367 \\
\hline & B25 & LC004306 & LC004331, LC004332 & LC004368 \\
\hline & $\mathrm{B} 27$ & & LC004333, LC004334 & LC004369, LC004370 \\
\hline & B28 & & LC004335, LC004336 & LC004371, LC004372, LC004373 \\
\hline & B34 & & LC004337, LC004338 & \\
\hline Total & & 9 & 32 & 35 \\
\hline
\end{tabular}

the B. bovis MSA-1, MSA-2b, and MSA-2c genes. From 18 of the $39 \mathrm{~B}$. bovis-positive DNA samples, at least one target gene was amplifiable with these PCR assays (12 from cattle and six from water buffaloes) (Table 1 ). Whereas 15 and $16 B$. bovis-positive DNA samples were positive for $M S A-2 b$ and $M S A-2 c$, respectively, the $M S A-1$ gene was amplified from only five DNA samples. Of the two forward primers used to amplify the MSA-1 gene (Sivakumar et al., 2013b), only MSA-1 F1 generated PCR amplicons. Three clones were sequenced for each PCR product, and only representative sequences were submitted to GenBank, as shown in Table 1. Sequencing three clones per DNA sample often yielded different variants of an MSA gene, and identical sequences were rarely obtained from all three clones derived from a single DNA sample. Therefore, nine MSA-1 gene sequences (accession numbers LC004298-LC004306), 32 MSA-2b gene sequences (accession numbers LC004307-LC004338), and 35 MSA-2c gene sequences (accession numbers LC004339-LC004373) were registered with GenBank (Table 1).

The MSA-1 and MSA-2b gene sequences were 823-901 bp and 789-936 bp in length, respectively, whereas all the MSA-2c sequences were $798 \mathrm{bp}$. The nucleotide diversity per site (Pi), calculated with the DnaSP v5 software, was relatively higher for the $M S A-1$ (0.25375) and MSA-2b sequences (0.15728) than for MSA2c (0.05025) (Table 2). The Pi value for the MSA-1 gene sequences from cattle (0.23571) was higher than that for the water-buffaloderived sequences (0.19834), whereas the Pi values for cattle- and water-buffalo-derived $M S A-2 b$ ( 0.15331 and 0.15856 , respectively) and MSA-2c (0.04902 and 0.05022, respectively) were similar in both host animals. Similarly, the sequence identities of the MSA-1 (63.5\%-99.9\%) and $M S A-2 b$ sequences (68.7\%-100.0\%) were relatively lower than those of the MSA-2c sequences (91.4\%-99.9\%) (Table 2 and Figs. S1-S3). In contrast, the sequence identities of cattle- and water-buffalo-derived MSA-1 (63.6\%-99.9\% and 63.5\%-99.9\%, respectively), MSA-2b (68.9\%-100\% and 72.3-99.9\%, respectively), and $M S A-2 c$ (both $92.0 \%-99.9 \%$ ) were similar in the two hosts. In agreement with the Pi values and sequence identity scores, the B-cell epitopes predicted among Vietnamese MSA-2c amino acid sequences were relatively conserved, while those of MSA-1 and MSA-2b sequences were diverse (Table 3).

In the phylogenetic analyses, the MSA-1 gene sequences determined in this study occurred in four separate clades (clades 1, 3,
Table 2

Nucleotide diversities and identities of the MSA-1, MSA-2b, and MSA-2c gene sequences from cattle and water buffaloes in Vietnam.

\begin{tabular}{lllll}
\hline Gene & Source & Numbers & Pi \pm SD & Identity (\%) \\
\hline MSA-1 & Cattle & 6 & $0.23571 \pm 0.05087$ & $63.6-99.9$ \\
& Buffaloes & 3 & $0.19834 \pm 0.09314$ & $63.5-99.9$ \\
& Cattle and buffaloes & 9 & $0.25375 \pm 0.02426$ & $63.5-99.9$ \\
MSA-2b & Cattle & 23 & $0.15331 \pm 0.00935$ & $68.9-100$ \\
& Buffaloes & 9 & $0.15856 \pm 0.01381$ & $72.3-99.9$ \\
& Cattle and buffaloes & 32 & $0.15728 \pm 0.00550$ & $68.7-100$ \\
MSA-2c & Cattle & 24 & $0.04902 \pm 0.00262$ & $92.0-99.9$ \\
& Buffaloes & 11 & $0.05022 \pm 0.00617$ & $92.0-99.9$ \\
& Cattle and buffaloes & 35 & $0.05025 \pm 0.00255$ & $91.4-99.9$ \\
\hline
\end{tabular}

$\mathrm{Pi}$, nucleotide diversity per site.

$\mathrm{SD}$, standard deviation.

6, and 8) (Fig. 1). Two of these clades (clades 1 and 6) were formed exclusively by sequences determined in this study, whereas the other two clades (clades 3 and 8) included MSA-1 sequences from Vietnam, Sri Lanka, and the Philippines. With the exception of clade 6 , the cattle- and water-buffalo-derived Vietnamese sequences were dispersed in separate clades (i.e., cattle-derived sequences in clades 1 and 8 and water-buffalo-derived sequences in clade 3). However, the water-buffalo-derived Vietnamese sequences in clade 3 clustered together with those reported from cattle in Sri Lanka and the Philippines (Fig. 1). In contrast, the $M S A-2 b$ sequences determined in this study occurred in eleven (clades 1, 5, 7, 10-14, and 20-22) of the twenty-two clades on the phylogenetic tree (Fig. 2). The Vietnamese MSA-2b sequences often clustered with the sequences from several other countries. Among the $M S A-2 b$ sequences determined in the present study, water-buffalo-derived sequences were found in five separate clades (clades 1, 7, 11, 20, and 21), and two of them (clades 1 and 21) included cattle-derived sequences as well. However, in addition to the water-buffalo-derived $M S A-2 b$ sequence (LC004331) generated in the present study, two previously determined sequences (Sivakumar et al., 2013a) sourced from a Vietnamese cattle (AB786920) and a water buffalo (AB786923) were also found in clade 20 (Fig. 2). The phylogenetic tree of the 
Table 3

The diversity of amino acid residues in the B-cell epitopes predicted from Vietnamese MSA-1, MSA-2b, and MSA-2c sequences.

\begin{tabular}{|c|c|c|c|c|c|}
\hline \multicolumn{2}{|l|}{ MSA-1 } & \multicolumn{2}{|l|}{ MSA-2b } & \multicolumn{2}{|l|}{ MSA-2c } \\
\hline Epitopes $^{\mathrm{a}}$ & Conserved a aa/total aa & Epitopes & Conserved a aa/total aa & Epitopes & Conserved a aa/total aa \\
\hline FLMTAVCCVVSFAT $^{\mathrm{b}}$ & $10 / 14$ & KIFLLTACCCASLLSVSAS $^{\mathrm{b}}$ & $16 / 19$ & FNIITVAFCSILFTYTLASP ${ }^{\mathrm{b}}$ & $13 / 20$ \\
\hline DSIVVPPTHVPAASSRLLFED & $6 / 21$ & IANLITYL & $3 / 8$ & NGSHLLFD & $7 / 8$ \\
\hline NLMVKLDSS & $4 / 9$ & DCSRDALKALKDILVVLKEE & $5 / 20$ & HDALKAVKQLIKTD & $14 / 14$ \\
\hline MDSVIQIYHKT & $8 / 11$ & FKSLLERVLLIKK & $4 / 13$ & TLDLEYLSG & $9 / 9$ \\
\hline FKEHVFDSK & $3 / 9$ & YKKHISA & $4 / 7$ & LLKLLIEAI & $7 / 9$ \\
\hline SVRVGYA & $2 / 7$ & VKDYTFLVKFCNDY & $9 / 14$ & LSNLYKAFI & $6 / 9$ \\
\hline FVSIVSTAGLYFK & $3 / 13$ & MKIYKAF & $3 / 7$ & ALRIASE & $5 / 7$ \\
\hline SSSVVSES & $0 / 8$ & EELVKKK & $3 / 7$ & & \\
\hline KQPAPQSPSAD & $0 / 11$ & & & & \\
\hline
\end{tabular}

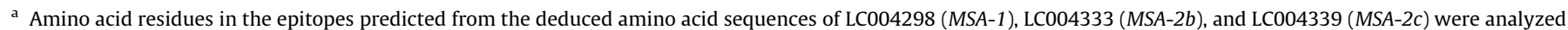
for their diversity among the Vietnamese sequences.

b Epitope detected within the signal peptide.

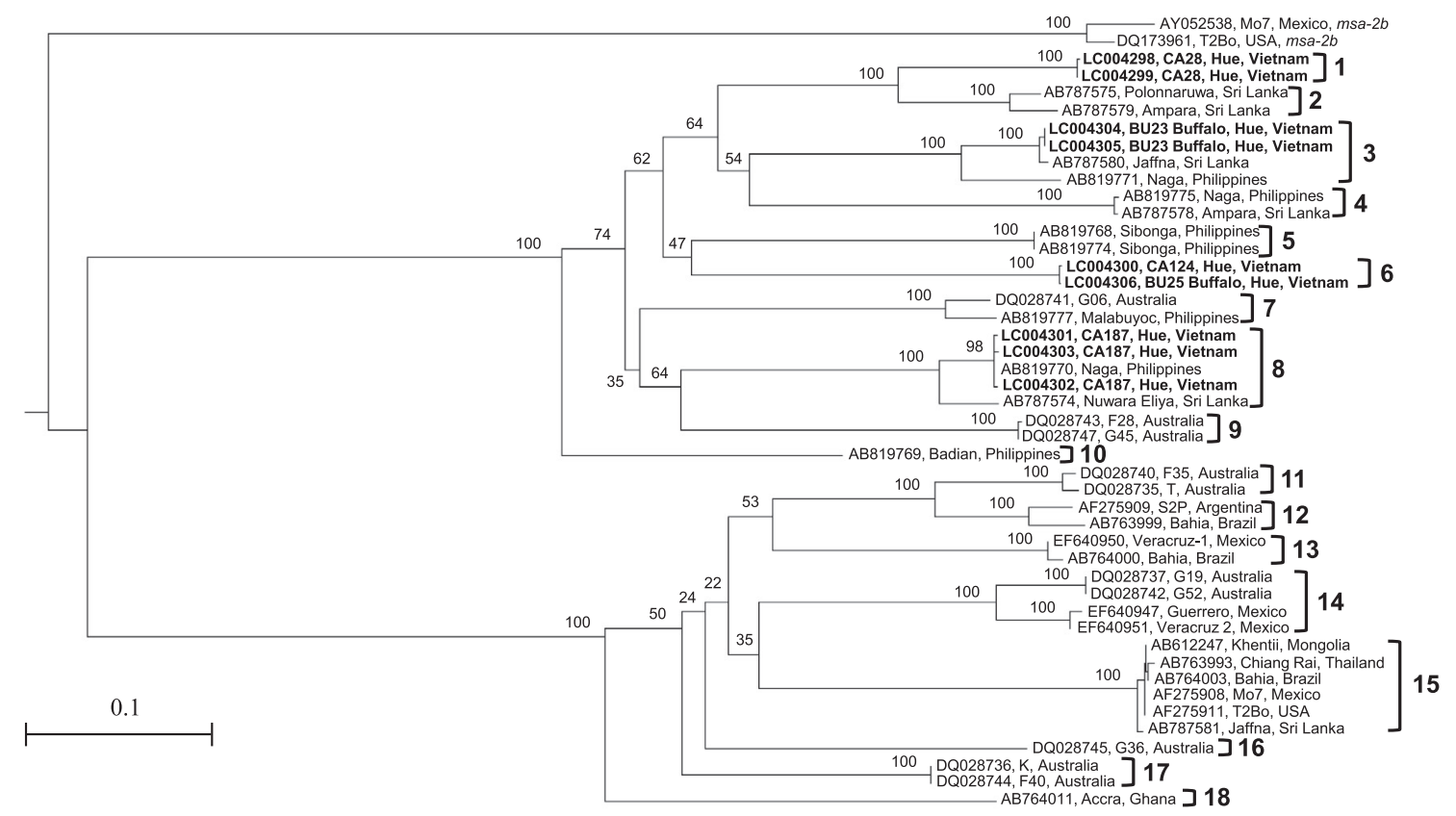

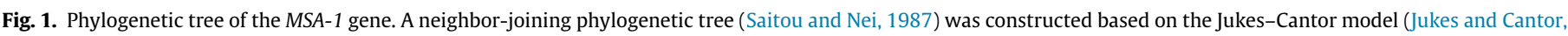

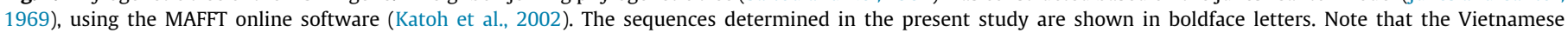
sequences are found across multiple clades and that clade 6 contains sequences from a Vietnamese cattle and a water buffalo.

MSA-2c gene divided the sequences into three major clades, and all of the sequences from Vietnamese cattle and water buffaloes occurred in a single clade (clade 3) (Fig. 3).

Recombination was investigated in all of the cattle- and waterbuffalo-derived MSA-1, MSA-2b, and MSA-2c gene sequences with automated methods hosted by RDP4 Beta 4.39. Seven potential recombination events were detected by three or more of the recombination detection methods used (Table 4). Among these, five were associated with $M S A-2 b$ recombinant sequences and the remaining two recombination events involved $M S A-2 c$ recombinant sequences. Except for event numbers 9 and 13, all the events were detected with more than three methods. Most of the recombination events involved recombination between sequences of the same gene, but in event 13, the MSA-1 sequence was detected as the minor parental sequence of the recombinant $M S A-2 b$ sequences. Recombination between the cattle- and water-buffalo-derived sequences was frequently detected, and the resultant recombinant sequences were found in cattle and/or water buffaloes (Table 4).

\section{Discussion}

Genetic diversity is thought to be a survival strategy of protozoan parasites (Deitsch et al., 2009). Antigenic variations arising from this genetic diversity result in different immune profiles in their host animals. The involvement of genetic diversity in the immune evasion of $B$. bovis is well documented in the literature (Berens et al., 2005; Leroith et al., 2005). Consequently, the genetic diversity among the MSA genes has been studied in several endemic countries (Altangeral et al., 2012; Berens et al., 2005; Borgonio et al., 2008; Genis et al., 2008, 2009; Leroith et al., 2005; Molad et al., 2014; Nagano et al., 2013; Sivakumar et al., 2013b; Tattiyapong et al., 2014). Almost all these studies invariably focused on the genetic diversity of the MSA genes of $B$. bovis derived from cattle, whereas $B$. bovis in buffaloes has rarely been investigated, although this host species is considered to play a significant role in its epidemiology (da Silva et al., 2013; Elsify et al., 2015; He et al., 2012; Sivakumar et al., 2013a). Therefore, in this study, we investigated the diversity in the B. bovis MSA-1, 


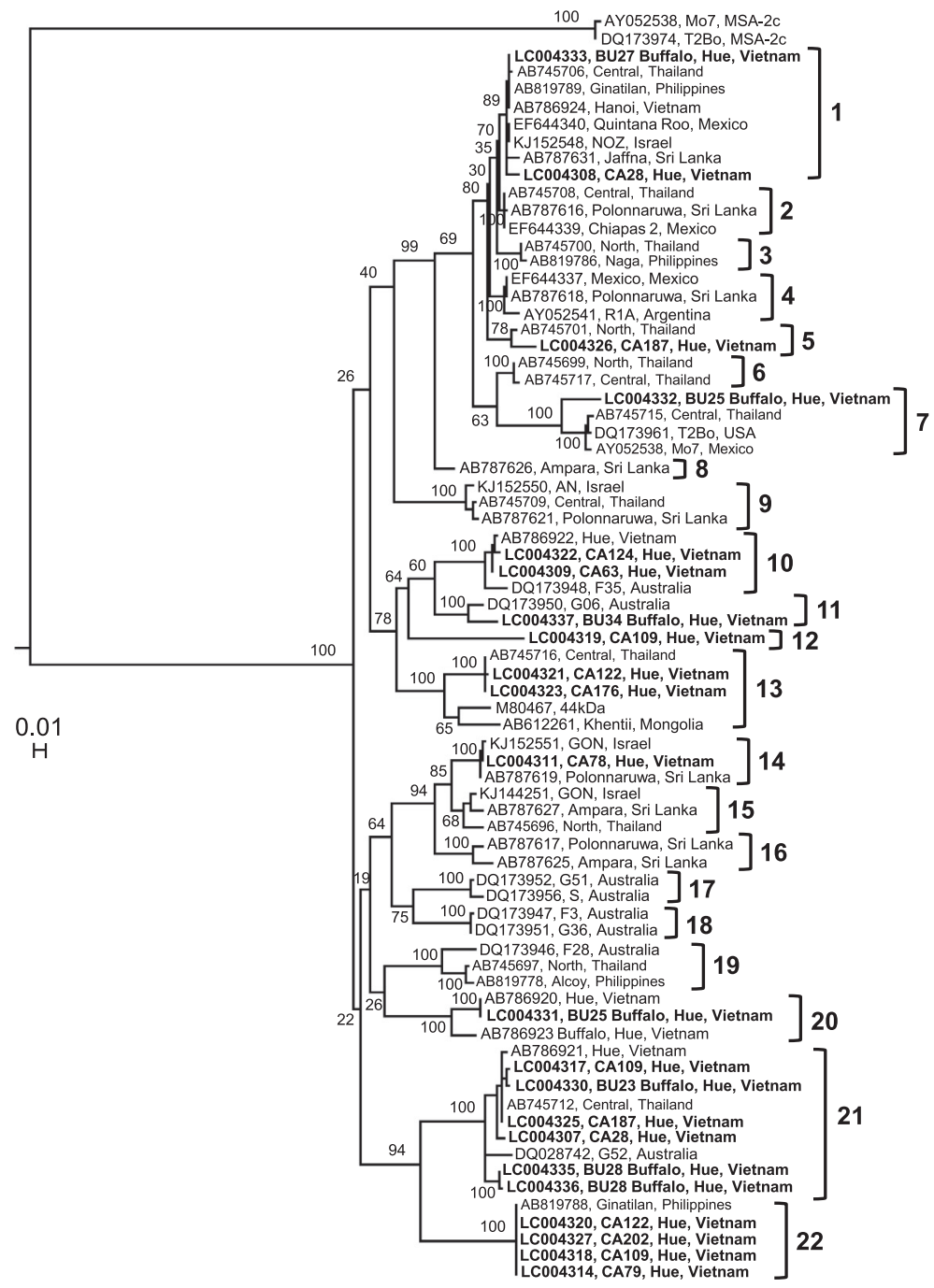

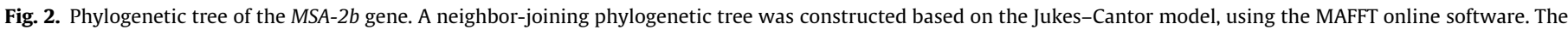

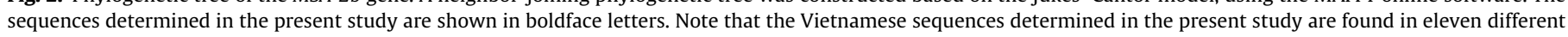
clades (clades 1, 5, 7, 10-14, and 20-22) and that the water-buffalo-derived sequences often cluster together with those from cattle.

$M S A-2 b$, and MSA-2c genes from both cattle and water buffaloes bred in Vietnam.

According to previous studies, B. bovis is endemic in Vietnamese cattle and water buffaloes (Hau et al., 1999; Sivakumar et al., 2013a). Consistent with those studies, we found that both the cattle and water buffalo populations surveyed in the present study included $B$. bovis-positive animals. The MSA-1, MSA-2b, and $M S A-2 c$ genes were amplified and sequenced. Although 39 DNA samples were positive for B. bovis, the MSA genes were amplified from only 18 samples. The differences in the sensitivity of the PCR assays that we used could explain this discrepancy, because the diagnostic screening was based on a highly sensitive nested PCR assay (Figueroa et al., 1993), whereas the MSA genes were amplified with single-step PCR assays. The lowest number of sequences was determined for the MSA-1 gene. Both the glycosylphosphatidylinositol-anchor and signal-peptide regions are conserved in MSA- $2 b$ and $M S A-2 c$, whereas the signal-peptide region of the $M S A-1$ gene is not strictly conserved (Sivakumar et al., 2013b). Therefore, based on the currently available sequences, two forward primers were used to amplify MSA-1 (Sivakumar et al., 2013b). However, there might be other MSA-1 variants that cannot be amplified with the primer sets used in this study, which could explain the low numbers of $M S A-1$ gene sequences determined here.

A previous study detected several MSA-1 variants in individual carrier animals, suggesting that these animals were co-infected with more than one B. bovis strain (Lau et al., 2010). Tick vectors feed on such carriers might become co-infected, and their progenies may transmit multiple strains of $B$. bovis, simultaneously. This might explain why most of the $B$. bovis-infected animals in the present study were detected with multiple MSA variants, although the parasite-positive rate among the cattle was very low. On the other hand, although the sequences determined from a single PCR amplicon were often non-identical, most of them shared high identity scores. The DNA polymerase that we used to amplify the MSA genes is not a high fidelity enzyme, and therefore, the replication errors that could have resulted in minor variations among such sequences cannot be entirely ruled out. However, together with the field DNA samples, the plasmids containing the inserts of $M S A-1, M S A-2 b$, and $M S A-2 c$ genes with known nucleotide sequences were also amplified, cloned, and sequenced. The sequences of these controls were identical to those of previously determined, suggesting that the replication errors were unlikely. 


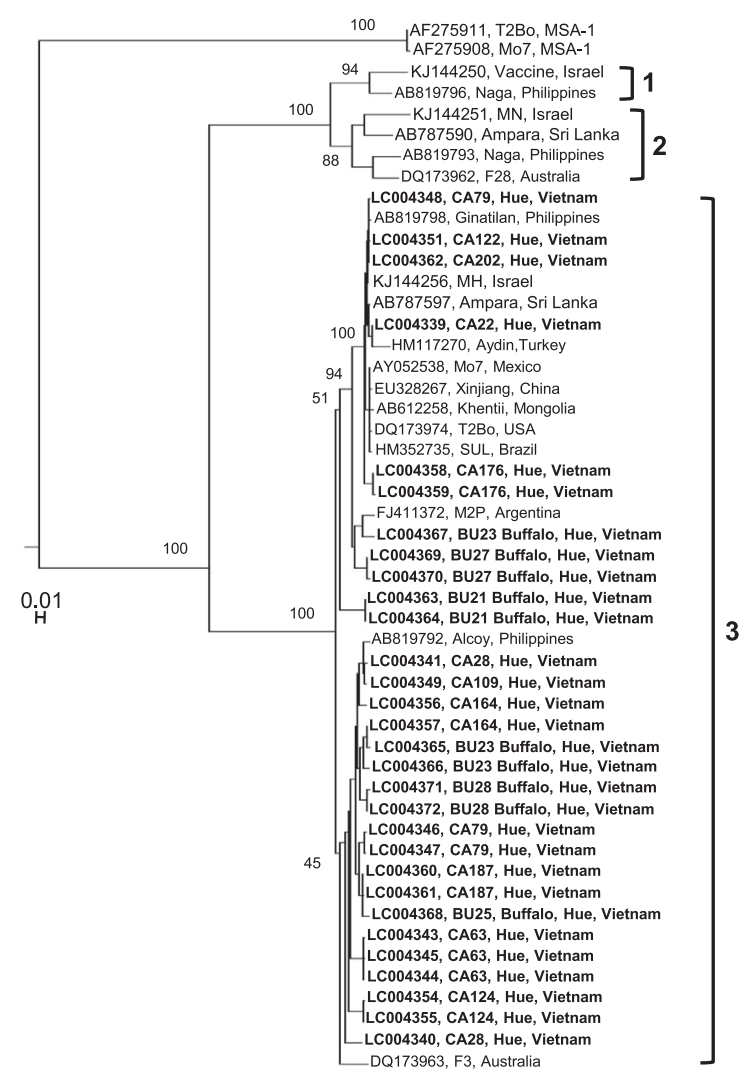

Fig. 3. Phylogenetic tree of the MSA-2c gene. A neighbor-joining phylogenetic tree was constructed based on the Jukes-Cantor model, using the MAFFT online software. The sequences determined in the present study are shown in boldface letters. Note that all the Vietnamese sequences from cattle and water buffaloes occur in a single clade (clade 3 ).

The nucleotide identities among the $B$. bovis MSA genes were similar in the cattle and water buffaloes in Vietnam. The Pi values were also similar for the cattle- and water-buffalo-derived sequences of the MSA- $2 b$ and $M S A-2 c$ genes. However, the Pi value for the MSA-1 sequences was lower in water buffaloes than in cattle, possibly because fewer sequences $(n=3)$ were amplified from water buffaloes. Nevertheless, these observations suggest that the levels of genetic diversity in the $B$. bovis MSA genes are similar in the cattle and water buffaloes of Vietnam. The MSA-2c gene is diverse in Australia (Berens et al., 2005), Sri Lanka (Sivakumar et al., 2013b), the Philippines (Tattiyapong et al., 2014), and Israel (Molad et al., 2014), whereas this gene is conserved in Mongolia (Altangeral et al., 2012) and Brazil (Ramos et al., 2012). In addition, the sequences isolated in Argentina, Mexico, and USA shared high similarities, suggesting that the $M S A-2 c$ from distant geographical locations may also sometimes be conserved (Dominguez et al., 2010; Florin-Christensen et al., 2002). In Vietnam, the genetic diversity of the MSA-2c gene seems lower than that of the MSA-1 and MSA- $2 b$ genes, at least among the sequences analyzed in the present study. Consistent with the sequencing analyses, the Vietnamese MSA-1 and MSA- $2 b$ sequences were dispersed across several clades on the phylogenetic trees, whereas the MSA-2c sequences were detected in a single clade. In the phylogenetic analyses, the sequences of the MSA- $2 b$ and $M S A-2 c$ genes from cattle and water buffaloes were often detected in the same clades, suggesting that the phylogenetic positions of the B. bovis MSA gene sequences do not differ between the cattle and water buffaloes in Vietnam.

The high genetic variation among the $B$. bovis MSA genes is thought to be driven by genetic recombination in the tick vectors (Berens et al., 2005; Simuunza et al., 2011). The gene sequences identified in the present study were analyzed with seven automated methods of detecting recombination, using RDP4 Beta 4.39 (Martin and Rybicki, 2000). Seven potential recombination events were detected, involving 19 recombinant sequences of $M S A-2 b$ and MSA-2c. Recombination was also detected between the cattle- and water-buffalo-derived sequences, with no host specificity, and the resultant recombinants were found in both species. $B$. bovis is usually transmitted by one-host tick species, and therefore the parental sequences for recombination arguably derive from a single host animal. So that, the detection of recombination events between the cattle- and water-buffalo-derived sequences infers the existence of water-buffalo-derived sequences in cattle or cattle-derived sequences in water buffaloes in Vietnam. Cattle and water buffaloes in the surveyed locations are used to be in close contact during grazing, allowing the tick-transmission of $B$. bovis between these host animals. Therefore, it is unlikely, at least in Vietnam, that the MSA variants in cattle and water buffaloes differ. Six of seven recombination events were detected between homologous gene sequences. In contrast, event 13 involved MSA$2 b$ genes as the recombinant and the major parental sequences, but the MSA-1 gene was the minor parental sequence. However, because the similarity values between the recombinant and parental sequences were low (data not shown), the reliability of this recombination event is dubious. In contrast, no recombinant sequences were found among the Vietnamese MSA-1 gene sequences. Similar to our findings, no recombination sites were detected among the MSA-1 gene sequences analyzed in a previous study (Leroith et al., 2005). We believe that the analysis of large numbers of MSA-1 gene sequences might shed some light on the role of recombination in generating the diversity observed in this gene.

The high genetic diversity of MSA gene sequences might be a limitation for the use of these antigens as recombinant vaccines. LeRoith et al. (2005) and Berens et al. (2005) demonstrated that the genetic variations of MSA gene sequences might be linked to the lack of protection by the vaccine strains. In contrast, Suarez et al. (2000) showed that the antibodies raised against recombinant MSA-1 of B. bovis R1A strain effectively inhibit the erythrocyte invasion of Mo7 strain, despite the low similarity shared between the MSA-1 amino acid sequences from these strains. Therefore, additional studies using immunoblot assays and neutralization tests are essential to explore the possibility of using these antigens as vaccines in Vietnam. On the other hand, although the B-cell epitopes predicted from MSA- 1 and MSA-2b sequences were found to be diverse, these epitopes were relatively conserved within a particular clade (data not shown), suggesting that the inclusion of antigens representing different clades in the phylogeny might overcome this constraint.

In summary, in this study, an analysis of the genetic diversity among the B. bovis MSA-1, MSA-2b, and MSA-2c genes showed that the patterns of diversity do not differ between the cattle- and water-buffalo-derived sequences in Vietnam. Our findings also suggest that recombination might be a common event between the $M S A-2 b$ and the $M S A-2 c$ gene sequences derived from cattle and water buffaloes, and could contribute to the genetic diversity of these genes in Vietnam. 


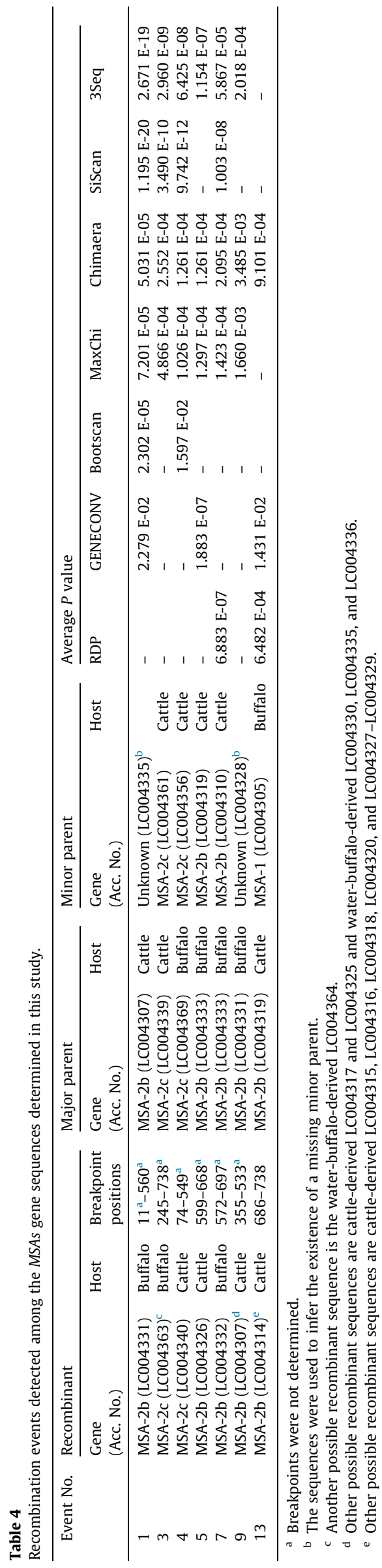

\section{Acknowledgments}

We thank all the staff and farmers on the farms surveyed in Vietnam. We are also grateful to Ms. Hiroko Yamamoto, National Research Center for Protozoan Diseases, Obihiro University of Agriculture and Veterinary Medicine, for her excellent technical assistance. This study was supported by grants from JSPS KAKENHI (23405041 and 25660235) and the JST/JICA, Science and Technology Research Partnership for Sustainable Development (SATREPS).

\section{References}

Altangeral, K., Sivakumar, T., Battsetseg, B., Battur, B., Ueno, A., Igarashi, I., Yokoyama, N., 2012. Phylogenic relationship of Mongolian Babesia bovis isolates based on the merozoite surface antigen (MSA)-1, MSA-2b, and MSA2c genes. Vet. Parasitol. 184, 309-316.

Berens, S.J., Brayton, K.A., Molloy, J.B., Bock, R.E., Lew, A.E., McElwain, T.F., 2005 Merozoite surface antigen 2 proteins of Babesia bovis vaccine breakthrough isolates contain a unique hypervariable region composed of degenerate repeats. Infect. Immun. 73, 7180-7189.

Bock, R.E., de Vos, A.J., 2001. Immunity following use of Australian tick fever vaccine: a review of the evidence. Aust. Vet. J. 79, 832-839.

Bock, R.E., Jackson, L., de Vos, A., Jorgensen, W., 2004. Babesiosis of cattle. Parasitology 129 (Suppl.), S247-S269.

Boni, M.F., Posada, D., Feldman, M.W., 2007. An exact nonparametric method for inferring mosaic structure in sequence triplets. Genetics 176, 1035-1047.

Borgonio, V., Mosqueda, J., Genis, A.D., Falcon, A., Alvarez, J.A., Camacho, M., Figueroa J.V., 2008. MSA-1 and MSA-2c gene analysis and common epitopes assessment in Mexican Babesia bovis isolates. Ann. N. Y. Acad. Sci. 1149, 145-148.

Brown, W.C., Palmer, G.H., 1999. Designing blood-stage vaccines against Babesia bovis and B. bigemina. Parasitol. Today 15, 275-281.

Campanella, J.J., Bitincka, L., Smalley, J., 2003. MatGAT: an application that generates similarity/identity matrices using protein or DNA sequences. BMC Bioinformatics 10 (4), 29.

da Silva, J.B., André, M.R., da Fonseca, A.H., de Albuquerque Lopes, C.T., da Silva Lima D.H., de Andrade, S.J., Oliveira, C.M., Barbosa, J.D., 2013. Molecular and serological prevalence of Babesia bovis and Babesia bigemina in water buffaloes in the north region of Brazil. Vet. Parasitol. 197, 678-681.

Deitsch, K.W., Lukehart, S.A., Stringer, J.R., 2009. Common strategies for antigenic variation by bacterial, fungal and protozoan pathogens. Nat. Rev. Microbiol. 7, 493-503.

Dominguez, M., Echaide, I., Echaide, S.T., Mosqueda, J., Cetrá, B., Suarez, C.E., FlorinChristensen, M., 2010. In silico predicted conserved B-cell epitopes in the merozoite surface antigen-2 family of $B$. bovis are neutralization sensitive. Vet. Parasitol. 167, 216-226.

Elsify, A., Sivakumar, T., Nayel, M., Salama, A., Elkhtam, A., Rizk, M., Mosaab, O., Sultan, K., Elsayed, S., Igarashi, I., Yokoyama, N., 2015. An epidemiological survey of bovine Babesia and Theileria parasites in cattle, buffaloes, and sheep in Egypt. Parasitol. Int. 64, 79-85.

Everitt, J.I., Shadduck, J.A., Steinkamp, C., Clabaugh, G., 1986. Experimental Babesia bovis infection in Holstein calves. Vet. Pathol. 23, 556-562.

Figueroa, J.V., Chieves, L.P., Johnson, G.S., Buening, G.M., 1993. Multiplex polymerase chain reaction based assay for the detection of Babesia bigemina, Babesia bovis and anaplasma marginale DNA in bovine blood. Vet. Parasitol. 50, 69-81.

Florin-Christensen, M., Suarez, C.E., Hines, S.A., Palmer, G.H., Brown, W.C. McElwain, T.F., 2002. The Babesia bovis merozoite surface antigen 2 locus contains four tandemly arranged and expressed genes encoding immunologically distinct proteins. Infect. Immun. 70, 3566-3575.

Genis, A.D., Mosqueda, J.J., Borgonio, V.M., Falcón, A., Alvarez, A., Camacho, M., de Lourdes Muñoz, M., Figueroa, J.V., 2008. Phylogenetic analysis of Mexican Babesia bovis isolates using msa and ssrRNA gene sequences. Ann. N. Y. Acad. Sci. 1149, 121-125.

Genis, A.D., Perez, J., Mosqueda, J.J., Alvarez, A., Camacho, M., Munoz Mde, L., Rojas C., Figueroa, J.V., 2009. Using MSA-2b as a molecular marker for genotyping Mexican isolates of Babesia bovis. Infect. Genet. Evol. 9, 1102-1107.

Geurden, T., Somers, R., Thanh, N.T., Vien, L.V., Nga, V.T., Giang, H.H., Dorny, P., Giao H.K., Vercruysse, J., 2008. Parasitic infections in dairy cattle around Hanoi, northern Vietnam. Vet. Parasitol. 153, 384-388.

Gibbs, M.J., Armstrong, J.S., Gibbs, A.J., 2000. Sister-Scanning: a Monte Carlo procedure for assessing signals in recombinant sequences. Bioinformatics 16 , $573-582$.

Hau, N.V., Thu, N.V., Hanh, H.T., Sat, L.M., 1999. A preliminary study on application of polymerase chain reaction in diagnosis of haemosporidiosis in cattle. Khoa. Hoc. Ky. Thuat. Thu. Y. 6, 48-52. 
He, L., Feng, H.H., Zhang, W.J., Zhang, Q.L., Fang, R., Wang, L.X., Tu, P., Zhou, Y.Q., Zhao, J.L., Oosthuizen, M.C., 2012. Occurrence of Theileria and Babesia species in water buffalo (Bubalus babalis, Linnaeus, 1758) in the Hubei province, South China. Vet. Parasitol. 186, 490-496.

Hines, S.A., Palmer, G.H., Jasmer, D.P., McGuire, T.C., McElwain, T.F. 1992. Neutralization-sensitive merozoite surface antigens of Babesia bovis encoded by members of a polymorphic gene family. Mol. Biochem. Parasitol. 55, 85-94.

Jukes, T.H., Cantor, C.R., 1969. Evolution of Protein Molecules. In: Munro, H.N. (Ed.). Academic Press, New York, pp. 21-132.

Katoh, K., Misawa, K., Kuma, K., Miyata, T., 2002. MAFFT: a novel method for rapid multiple sequence alignment based on fast Fourier transform. Nucleic Acids Res. 30, 3059-3066.

Khukhuu, A., Lan, D.T., Long, P.T., Ueno, A., Li, Y., Luo, Y., Macedo, A.C., Matsumoto, K., Inokuma, H., Kawazu, S., Igarashi, I., Xuan, X., Yokoyama, N., 2011. Molecular epidemiological survey of Theileria orientalis in Thua Thien Hue Province, Vietnam. J. Vet. Med. Sci. 73, 701-705.

Kolaskar, A.S., Tungaonkar, P.C., 1990. A semi-empirical method for prediction of antigenic determinants on protein antigens. FEBS Lett. 276, 172-174.

Lau, A.O., Cereceres, K., Palmer, G.H., Fretwell, D.L., Pedroni, M.J., Mosqueda, J., McElwain, T.F., 2010. Genotypic diversity of merozoite surface antigen 1 of Babesia bovis within an endemic population. Mol. Biochem. Parasitol. 172, $107-$ 112.

Leroith, T., Brayton, K.A., Molloy, J.B., Bock, R.E., Hines, S.A., Lew, A.E., McElwain, T.F., 2005. Sequence variation and immunologic cross-reactivity among Babesia bovis merozoite surface antigen 1 proteins from vaccine strains and vaccine breakthrough isolates. Infect. Immun. 73, 5388-5394.

Librado, P., Rozas, J., 2009. DnaSP v5: a software for comprehensive analysis of DNA polymorphism data. Bioinformatics 25, 1451-1452.

Martin, D.P., Posada, D., Crandall, K.A., Williamson, C., 2005. A modified bootscan algorithm for automated identification of recombinant sequences and recombination breakpoints. AIDS Res. Hum. Retroviruses 21, 98-102.

Martin, D., Rybicki, E., 2000. RDP: detection of recombination amongst aligned sequences. Bioinformatics 16, 562-563.

Maynard Smith, J., 1992. Analyzing the mosaic structure of genes. J. Mol. Evol. 34 $126-129$.

Molad, T., Fleiderovitz, L., Leibovich, B., Wolkomirsky, R., Erster, O., Roth, A., Mazuz, M.L., Markovics, A., Shkap, V., 2014. Genetic polymorphism of Babesia bovis merozoite surface antigens-2 (MSA-2) isolates from bovine blood and Rhipicephalus annulatus ticks in Israel. Vet. Parasitol. 205, 20-27.

Nagano, D., Sivakumar, T. De Macedo, A.C. Inpankaew, T, Alhassan, A., Igarashi, I. Yokoyama, N., 2013. The genetic diversity of merozoite surface antigen 1 (MSA 1) among Babesia bovis detected from cattle populations in Thailand, Brazil and Ghana. J. Vet. Med. Sci. 75, 1463-1470.

Padidam, M., Sawyer, S., Fauquet, C.M., 1999. Possible emergence of new geminiviruses by frequent recombination. Virology 265, 218-225.

Palmer, G.H., McElwain, T.F., 1995. Molecular basis for vaccine development against anaplasmosis and babesiosis. Vet. Parasitol. 57, 233-253.
Posada, D., Crandall, K.A., 2001. Evaluation of methods for detecting recombination from DNA sequences: computer simulations. Proc. Natl. Acad. Sci. 98, 1375713762.

Ramos, C.A., Araújo, F.R., Alves, L.C., de Souza, I.I., Guedes Jr., D.S., Soares, C.O., 2012. Genetic conservation of potentially immunogenic proteins among Brazilian isolates of Babesia bovis. Vet. Parasitol. 187, 548-552.

Ristic, M., 1981. Babesiosis. In: Ristic, M., MacIntyre, I. (Eds.), Diseases of Cattle in the Tropics. Martinus Nijhoff Publishers, The Hague, The Netherlands, pp. 443-468.

Saitou, N., Nei, M., 1987. The neighbor-joining method: a new method for reconstructing phylogenetic trees. Mol. Biol. Evol. 4, 406-425.

Shkap, V., de Vos, A.J., Zweygarth, E., Jongejan, F., 2007. Attenuated vaccines for tropical theileriosis, babesiosis, and heartwater: the continuing necessity. Trends Parasitol. 23, 420-426.

Simking, P., Saengow, S., Bangphoomi, K., Sarataphan, N., Wongnarkpet, S., Inpankaew, T., Jittapalapong, S., Munkhjargal, T., Sivakumar, T., Yokoyama, N., Igarashi, I., 2013. The molecular prevalence and MSA-2b gene-based genetic diversity of Babesia bovis in dairy cattle in Thailand. Vet. Parasitol. 197, 642648.

Simuunza, M., Bilgic, H., Karagenc, T., Syakalima, M., Shiels, B., Tait, A., Weir, W. 2011. Population genetic analysis and sub-structuring in Babesia bovis. Mol. Biochem. Parasitol. 177, 106-115.

Sivakumar, T., Altangerel, K., Battsetseg, B., Battur, B., AbouLaila, M., Munkhjargal, T., Yoshinari, T., Yokoyama, N., Igarashi, I., 2012a. Genetic detection of Babesia bigemina from Mongolian cattle using apical membrane antigen-1 gene based PCR assay. Vet. Parasitol. 187, 17-22.

Sivakumar, T. Kothalawala, H., Abeyratne, A.S, Vimalakumar, S.C., Meewawe, A.S. Hadirampela, D.T., Puvirajan, T., Sukumar, S., Kuleswarakumar, K., Chandrasiri, A.D.N., Igarashi, I., Yokoyama, N., 2012b. A PCR-based survey of selected Babesia and Theileria parasites in cattle in Sri Lanka. Vet. Parasitol. 190, 263-267.

Sivakumar, T., Lan, D.T., Long, P.T., Yoshinari, T., Tattiyapong, M., Guswanto, A., Okubo, K., Igarashi, I., Inoue, N., Xuan, X., Yokoyama, N., 2013a. PCR detection and genetic diversity of bovine hemoprotozoan parasites in Vietnam. J. Vet. Med. Sci. 75, 1455-1462.

Sivakumar, T., Okubo, K., Igarashi, I., de Silva, W.K., Kothalawala, H., Silva, S.S., Vimalakumar, S.C., Meewewa, A.S., Yokoyama, N., 2013b. Genetic diversity of merozoite surface antigens in Babesia bovis detected from Sri Lankan cattle. Infect. Genet. Evol. 19, 134-140.

Smith, R.D., Evans, D.E., Martins, J.R., Ceresér, V.H., Correa, B.L., Petraccia, C., Cardozo, H., Solari, M.A., Nari, A., 2000. Babesiosis (Babesia bovis) stability in unstable environments. Ann. N. Y. Acad. Sci. 916, 510-520.

Suarez, C.E., Florin-Christensen, M., Hines, S.A., Paler, G.H., Brown, W., McElwain, T.F., 2000. Characterization of allelic variation in the Babesia bovis merozoite surface antigen (MSA-1) locus and identification of a cross-reactive inhibitionsensitive MSA-1 epitope. Infect. Immun. 68, 6665-6670.

Tattiyapong, M., Sivakumar, T., Ybanez, A.P., Ybanez, R.H., Perez, Z.O., Guswanto, A., Igarashi, I., Yokoyama, N., 2014. Diversity of Babesia bovis merozoite surface antigen genes in the Philippines. Parasitol. Int. 63, 57-63. 